DOI: $10.33947 / 1980-6469-v 15 n 1-4004$

\title{
BULLYING: AS LEIS COMO UM AUXILIAR NO ENFRENTAMENTO DO FENÔMENO NAS ESCOLAS
}

\section{BULLYING: THE LAWS AS AN AUXILIAR IN COPING WITH THE PHENOMENON IN SCHOOLS}

\section{RESUMO}

Embora o bullying seja um fenômeno mundial, pouco se discute sobre a importância da legislação para o seu enfrentamento. Este artigo pretende abordar aspectos relevantes do fenômeno bullying entre os adolescentes, para compreender, interpretar e, ao final, indicar possíveis saídas a partir do olhar da educação e saúde, através de uma reflexão sobre a importância das leis existentes para o seu enfrentamento. Estudo qualitativo, descritivo, exploratório, bibliográfico, de leitura fenomenológica das legislações estaduais existentes sobre o bullying bem como das recentes legislações federais: a Lei $n^{\circ} 13.185$, sancionada em 06 de novembro de 2015 e a Lei $n^{\circ}$ 13.663/2018, que entrou em vigor em 15 de maio de 2018, sendo que ambas têm o objetivo de conscientização e prevenção do bullying. O conhecimento das leis possibilita que a equipe escolar, como um todo, em parceria com os pais e a sociedade obtenham parâmetros de orientação e formação que permitam oferecer educação aos adolescentes de forma a lhes garantir dignidade humana e igualdade, considerando as diferenças, bem como outros direitos básicos. PALAVRAS-CHAVE: Adolescente. Bullying. Legislação como assunto. Educação. Saúde.

\section{ABSTRACT}

Although bullying is a worldwide phenomenon, insufficient is said about legislation importance for its coping. This article intends to approach relevant aspects of bullying phenomenon among adolescents, to understand interpreting and, at the end, to indicate possible outputs from the education and health perspective, through a reflection on the existing laws importance for their confrontation. Qualitative, descriptive, exploratory, bibliographical study of phenomenological reading of existing state legislations about bullying as well as recent federal legislations: Law $n^{\circ} 13.185$, sanctioned on November 6, 2015 and Law $n^{\circ}$ 13.663/2018, which came into force on May 15, 2018, both of which have awareness and prevention aim of bullying. The laws knowledge enables school team (as a whole) in partnership with parents and society obtain orientation and training parameters to allow them to provide education to adolescents in order to guarantee them human dignity and equality, considering the differences, in addition other basic rights.

KEYWORDS: Adolescent. Bullying. Legislation as topic. Education. Health.

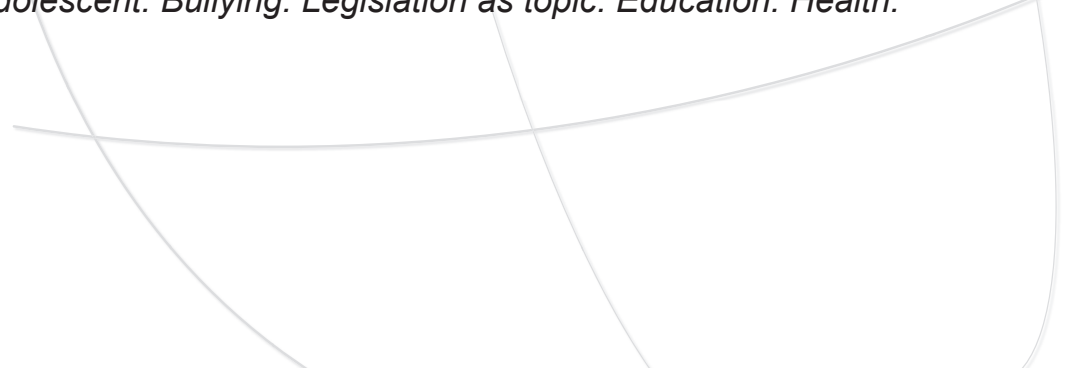

1 Mestre em Ciências pelo Programa de Pós-Graduação Educação e Saúde na Infância e na Adolescência, da Universidade Federal de São Paulo - Unifesp. Advogada pela Faculdade de Direito do Vale do Rio Doce - FADIVALE. Nota: Recebeu bolsa de estudos de mestrado financiada pela Coordenação de Aperfeiçoamento de Pessoal de Nível Superior - CAPES-REUNI.

2 Doutora em Ciências: Educação e Saúde na Infância e na Adolescência, pela Universidade Federal de São Paulo - UNIFESP; pedagoga e psicopedagoga, colaboradora no Setor de Medicina do Adolescente/Unifesp.

3 Profa. Ajunto Doutora do Setor de Medicina do Adolescente, Unifesp; Professor permanente do Programa de Pós-Graduação Educação e Saúde na Infância e na Adolescência. Autora correspondente: Maria Sylvia de Souza Vitalle, Setor de Medicina do Adolescente/ Departamento de Pediatria, Universidade Federal de São Paulo - UNIFESP. Endereço: Rua Botucatu, 715, Vila Clementino, CEP 04023-062, São Paulo, SP, Brasil. E-mail: sylviavitalle@gmail.com 
Introdução

A violência social é um desafio a ser enfrentado pelos sistemas educacionais brasileiros e não pode ser deixada na "porta de entrada" de uma escola. Assim, além dos conteúdos e disciplinas, a escola deve trabalhar a convivência, enfatizando as relações interpessoais e a mediação de conflitos, pois uma de suas tarefas educacionais é justamente a construção da possibilidade de conviver e de viver em conjunto, não deixando de lado as questões de violência em suas diferentes formas de manifestação no cenário escolar. Neste contexto, a violência na escola, manifestada pelas violências entre alunos (entre pares ou não) têm sido muito frequentes e preocupantes. Entre elas destaca-se o bullying, tema deste artigo. Olweus (2004), um dos primeiros pesquisadores a estudar bullying 0 definiu como sendo: "[...] uma conduta de perseguição física e/ou psicológica, de um aluno sobre outro que é eleito como vítima de repetidos ataques (p. 26)".

De acordo com Silva (2010, p.21) a expressão bullying, deriva da palavra inglesa bully (agressor), em cuja tradução é definida como: indivíduo valentão, tirano, mandão, brigão. Refere-se a atitudes de violência física e/ou psicológica, de caráter intencional e repetitivo, praticado por um bully em uma vítima, ou mais de uma, que não encontra possibilidade de defesa.

O termo bullying foi adotado no Brasil e em outros países por não se encontrar uma tradução que de fato represente seu significado, caracterizado como uma violência intencional e continuada sobre uma mesma vítima, geralmente entre iguais, por meio de intimidação, ameaças, constrangimentos, discriminação, agressões físicas, psicológicas e verbais que resultam em diversos danos à pessoa agredida. É uma prática que tem sido propagada nas instituições escolares e na internet (cyberbullying), principalmente entre os adolescentes (DUTRA, 2015).

A última edição da Pesquisa Nacional de Saúde do Escolar (Pense/2015), divulgada em agosto, aponta que quase metade dos 2,6 milhões de alunos entrevistados $(46,6 \%)$ já sofreu algum tipo de bullying, principalmente em relação à aparência, e se sentiu humilhado por colegas da escola. Na pesquisa anterior, realizada em 2012, esse índice era de $35,3 \%$. Entre os que praticam estão quase $20 \%$ dos estudantes.
Um estudo realizado por Marcolino el al. (2018) em escolas da rede pública de Campina Grande, na Paraíba, mostra que o sofrimento causado às vítimas de bullying atinge estudantes do sexo masculino e feminino, contudo é mais frequente entre os de sexo masculino, tanto como vítimas quanto como agressores. Estes autores encontraram que o bullying psicológico aparece em primeiro lugar, o físico em segundo e, em terceiro, o virtual (cyberbullying), sendo que os meninos têm mais chances de sofrer o bullying físico, praticado entre eles, se comparados com as meninas que sofrem mais bullying verbal.

Diferentemente de outras formas de bullying, o bullying psicológico, inclusive por seu aspecto mais subjetivo, pode ser considerado, em muitos casos, tanto pela equipe escolar como pelos pais, como algo a ser superado. Marcolino el al. (2018, p.07), afirmam que: "Esta tipologia encontra-se associada ao estereótipo de menor gravidade, o que contribui para o processo de naturalização dessas ações no convívio escolar. " Estas palavras alertam para o fato que, ao não se dar à vítima que sofre esta forma de agressão o cuidado e a atenção que necessita, seu sofrimento poderá se tornar maior do que o causado pelas outras formas de bullying.

Segundo Fante e Pedra (2008) o bullying ameaça o direito à educação, ao desenvolvimento, à saúde e à sobrevivência de muitas vítimas, sendo que, em um primeiro momento, ele precisa ser identificado no ambiente escolar, pois está presente em 100\% (cem porcento) das escolas no mundo inteiro, independentemente da sua localização, turno ou poder aquisitivo da comunidade escolar, quer sejam nas escolas públicas ou privadas.

Se a prática do bullying está presente em $100 \%$ das escolas no mundo todo, em um país continental como o Brasil, leva-nos a pensar a respeito da prevalência de bullying em suas diferentes regiões. Neste sentido, um estudo de MALTA (2014, p. 100) chamounos a atenção ao comparar as regiões Norte e Nordeste com Sul e Sudeste, apontando a região Sul do país com maior prevalência de bullying e a região Sudeste com maior prevalência de sua prática, como se pode ver:

[...] sofrer bullying apresentou maior prevalência na região Sul, $(8,2 \%$, IC95\% 8,0 - 8,4) e menor na região Norte $(5,7 \%$; IC95\% 4,0 - 7,3); a prática 
bullying foi maior na região Sudeste e Sul, respectivamente: $(23,6 \%$; IC95\% 20,9 - 26,4 e 23,2\%; IC95\% $21,7-24,8)$, e menor nas regiões Norte e Nordeste (16,5\%; IC95\% 16,0 - 17 e 16,1\%; IC95\% 13,5 - 18,6, respectivamente).

Nas últimas décadas, os adolescentes têm sido "enxergados" de forma especial pela sociedade, principalmente no que tange às discussões sobre os seus direitos e deveres, que vêm fomentando o âmbito jurídico, em parceria com a educação e a saúde, assegurar, cada vez mais, os adolescentes como sujeitos de direitos (DUTRA, 2015).

Nesse sentido, alguns Estados sairam à frente $\mathrm{e}$ preocuparam-se em legislar sobre o bullying, a fim de definir medidas para o enfrentamento deste fenômeno cuja prática causa tanto sofrimento. Ademais, buscando fundamentar as ações do Ministério da Educação e das Secretarias Estaduais e Municipais de Educação, bem como de outros orgãos responsáveis pelo assunto, foi sancionada a Lei Federal Brasileira, $\mathrm{n}^{\circ}$ 13.185/2015 (BRASIL, 2015), que institui o Programa de Combate à Intimidação Sistemática (Bullying). Não obstante, como já previsto, foi necessária a criação de uma nova lei, a Lei n 13.663/2018 (BRASIL, 2018), que entrou em vigor com o intuito de reduzir a elevada prevalência de bullying dentro das escolas. Seu texto incluiu dois incisos ao artigo 12 da Lei de Diretrizes e Bases da Educação Nacional (LDB - Lei 9.394/1996), determinando a promoção de medidas de conscientização, de prevenção e de combate a todos os tipos de violência e promoção da cultura de paz, entre as incumbências dos estabelecimentos de ensino.

Ante o exposto, este artigo pretende abordar aspectos relevantes do fenômeno bullying entre os adolescentes, sob o olhar jurídico, por meio de uma reflexão sobre a importância das leis existentes para o enfrentamento do bullying, compreendendo, interpretando e, ao final, indicando possíveis saídas a partir do olhar da educação e saúde.

\section{Percurso Metodológico}

Este artigo deriva da dissertação de mestrado, realizado pela primeira autora, intitulado "Bullying: $\mathrm{Da}$ Questão Legal ao Possível Enfrentamento do Fenôme- no nas Escolas" (DUTRA, 2015); O estudo atendeu à Resolução $n^{\circ} 466 / 12$, do Conselho Nacional de Saúde do Ministério da Saúde, que regulamenta as pesquisas envolvendo seres humanos, tendo sido aprovada pelo Comitê de Ética e Pesquisa da Universidade Federal de São Paulo/Hospital São Paulo, sob parecer n ${ }^{\circ}$ 5906261114 e trata-se de uma pesquisa bibliográfica, de natureza qualitativa, descritiva e exploratória, onde se procurou fazer uma leitura fenomenológica das leis sobre o bullying a fim de compreender e interpretar, buscando ao final sugerir caminhos possíveis para o seu combate.

Como forma de classificar a pesquisa, tomouse como base a taxionomia de Vergara (1998), que a qualifica em dois critérios: fins e meios. Quanto aos fins, ela é exploratória, uma vez que discute a realidade das leis que mencionam o bullying, no que tange ao processo de construção e implementação que deve ser vislumbrado de uma forma continuada, tendo como "[...] objetivo principal de aprimorar ideias ou a descoberta de instituições", conforme esclarece Gil (2008). Quanto aos meios, é bibliográfica, pois se utiliza de material escrito e impresso e material produzido em meio virtual. Nesse sentido, Köche (1997) reforça o objetivo deste tipo de pesquisa: "[...] conhecer e analisar as principais contribuições teóricas existentes sobre um determinado tema ou problema, tornando-se instrumento indispensável a qualquer tipo de pesquisa".

Desse modo, pretende-se apresentar algumas considerações a respeito das leis sobre o bullying, em seu aparato conteudístico, a partir da utilização da leitura fenomenológica hermenêutica. Com efeito, esta metodologia é fundamental por favorecer uma interpretação sobre a Lei, bem como permitir uma concepção subjetiva no processo de reflexão para as diversas perspectivas de análise.

A Fenomenologia Hermenêutica considera que toda a existência humana é interpretativa e apresenta um círculo: compreensão - interpretação - nova interpretação (GOMES, CARDOSO e SOUZA, 2014). Assim sendo, a abordagem realizada através deste olhar, é adequada para enfatizar a função das pesquisas qualitativas na busca por interpretar subjetivamente o legítimo sentido que está subentendido em textos, palavras e leis. Como afirma Martins apud Coltro (2000, p.39), esse método "[...] caracteriza-se pelo uso de 
técnicas não quantitativas com propostas críticas, buscando relacionar o fenômeno e a essência".

$\mathrm{Na}$ intersecção com o direito, o método se encaixa perfeitamente, pois a interpretação é imprescindível, segundo Couto (2014, p.32): "Interpretar em direito é, pois, estabelecer conexões de essências, é ligar o fundamento do fato ao fundamento da norma, corresponde a submeter o próprio pensamento puro da fantasia à autonormação".

\section{Resultados e discussão}

Durante o processo de construção da pesquisa foi realizado um levantamento das legislações específicas sobre o bullying, no âmbito federal, sendo localizados 19 (dezenove) projetos de leis em tramitação. Quanto aos Estados, foram localizadas 28 leis estaduais, cujos aspectos principais são mostrados no Quadro 1:

Quadro 1 - Legislações Estaduais de combate ao bullying e aspectos discorridos em cada uma:

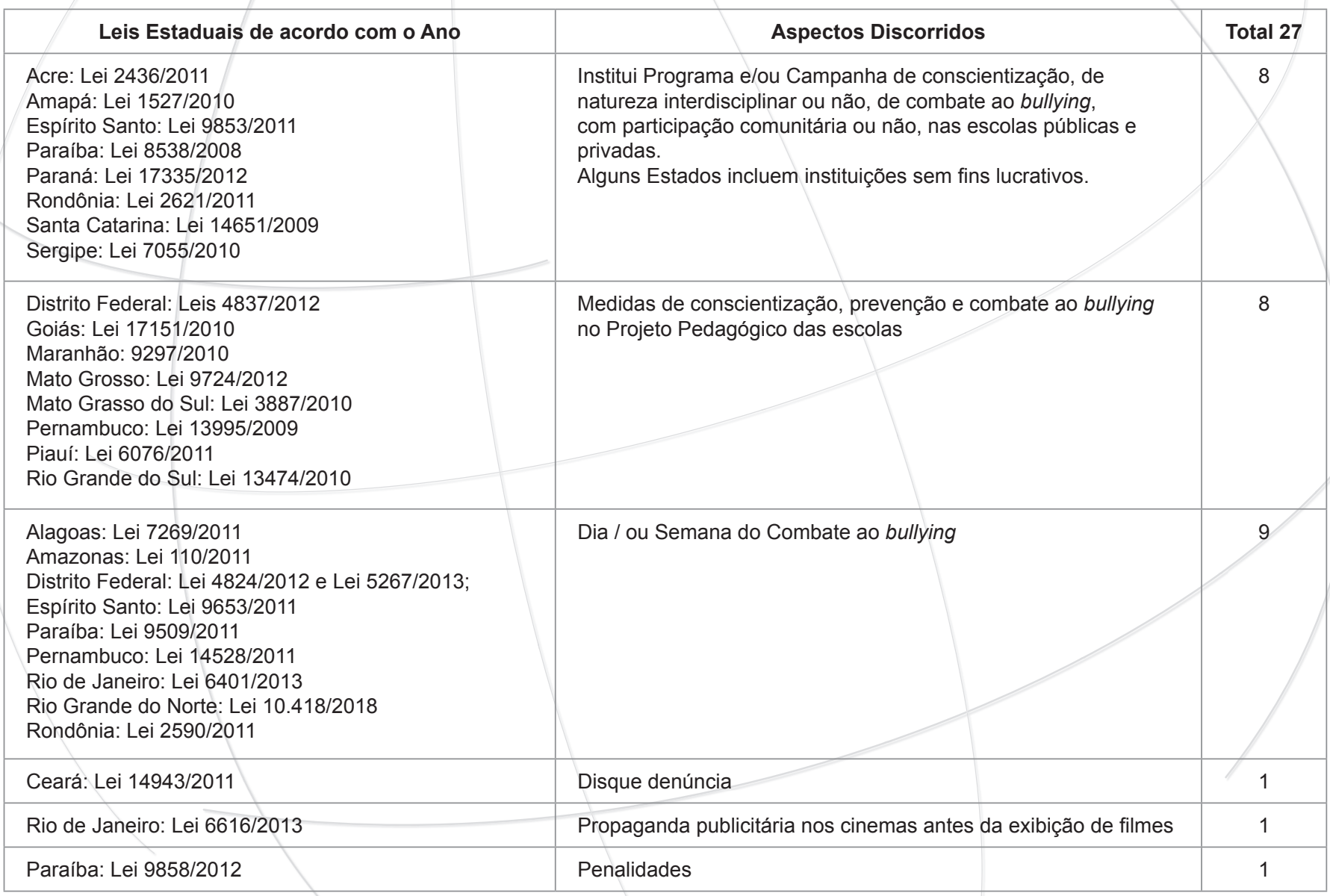


Observa-se a preocupação da maioria dos Estados em estabelecer disposições tratando da necessidade de conscientização, prevenção e orientação, explicitando a preocupação com esse tipo específico de violência. Oito Estados instituíram programas e/ ou campanha de conscientização, com participação comunitária, nas escolas públicas e privadas. Alguns, inclusive, incluíram sob o poder de suas leis as instituições sem fins lucrativos. Outros oito Estados consideram a importância de os Projetos Pedagógicos abordarem sob diferentes aspectos a questão do bullying e o preparo dos professores e equipe pedagógica para responderem positivamente ao enfrentamento dessa questão.

Dentre as Leis estaduais destacou-se a do Estado de Santa Catarina, de 2009, como exemplo de meIhor compreensão da eficácia do combate ao bullying por meio de implementação de lei. Esta Lei foi considerada um marco para se pensar e agir sobre este tema de forma objetiva e direta.

Em pesquisa realizada pela OAB de Santa Catarina (ADJORISC, 2013), foi identificado que $82 \%$ dos alunos convivem com o bullying e que grande parte já foi ou ainda é vítima da agressão. Apesar dos altos índices, verificou-se que o Estado é um dos únicos da federação que na ocasião estava realmente buscando combater este tipo de agressão por meio de uma campanha idealizada pela Promotoria de Justiça do Estado: "Bullying, isso não é brincadeira"; e aplicada através de folders, cartazes, gibis, marcadores de página e vídeos, que visavam a elucidar crianças, adolescentes, pais, responsáveis, professores, diretores e a sociedade em geral, sobre as formas e as conseqüências trazidas pelo fenômeno bullying, no intuito de contribuir para o conhecimento e, consequentemente, para seu combate e prevenção; e pela OAB/SC que vinha se empenhando em identificar o problema e buscar soluções.

Entretanto, verificou-se que esta legislação, embora apresentasse perspectivas apropriadas para o combate ao bullying escolar, também comporta algumas deficiências propositivas, como, por exemplo, a não garantia de critérios para que seu intento fosse efetivamente concretizado. Com efeito, uma alternativa seria definir responsabilidades compulsórias às escolas no caso de descumprimento da lei e fixar prazos para o planejamento de ações. Por que razão?

Uma razão pode estar relacionada ao desconhecimento das leis. Neste caso, das legislações sobre o combate ao bullying nas escolas. Outra razão pode estar relacionada às dificuldades de implantação da lei. As leis não apenas orientam, mas, sobretudo determinam, impõem uma obrigatoriedade, a quem se destinam. Além disso garantem direitos, e promovem o cumprimento dos deveres.

Em vista da necessidade cada vez mais premente de diretrizes orientadoras e meios de aplicação, em 06 de novembro de 2015, foi sancionada a Lei $n^{\circ} 13.185$, para instituir o Programa de Combate a Intimidação Sistemática (Bullying) em todo território nacional, trazendo em seu contexto o conceito de intimidação sistemática (Bullying), atribuindo características, classificando a intimidação sistemática conforme as ações praticadas e, assim, fundamentando as ações do Ministério da Educação e das Secretarias Estaduais e Municipais de Educação, bem como de outros órgãos.

Apresenta-se aqui, trechos da Lei. Em seu Art. $1^{\circ}$, a Lei refere-se ao Programa; no Art. $2^{\circ}$, traz a caracterização da intimidação sistemática: quando há violência física ou psicológica em atos de intimidação, humilhação ou discriminação e, ainda: I - ataques físicos; II - insultos pessoais; III - comentários sistemáticos e apelidos pejorativos; IV - ameaças por quaisquer meios; $\mathrm{V}$ - grafites depreciativos; $\mathrm{VI}$ - expressões preconceituosas; VII - isolamento social consciente e premeditado; VIII - pilhérias; bem como inclui o cyberbullying. Em seu Art. $3^{\circ}$, traz a classificação das formas de intimidação sistemática, quais sejam: "I - verbal: insultar, xingar e apelidar pejorativamente; II - moral: difamar, caluniar, disseminar rumores; III - sexual: assediar, induzir e/ou abusar; IV - social: ignorar, isolar e excluir; $\mathrm{V}$ - psicológica: perseguir, amedrontar, aterrorizar, intimidar, dominar, manipular, chantagear e infernizar; VI - físico: socar, chutar, bater; VII - material: furtar, roubar, destruir pertences de outrem; VIII - virtual: depreciar, enviar mensagens intrusivas da intimidade, enviar ou adulterar fotos e dados pessoais que resultem em sofrimento ou com o intuito de criar meios de constrangimento psicológico e social. Em seu Art. $4^{\circ}$ estão estabelecidos os objetivos referentes à: I - prevenir e combater a prática da intimidação sis- 
temática (bullying) em toda a sociedade; II - capacitar docentes e equipes pedagógicas para a implementação das ações de discussão, prevenção, orientação e solução do problema; III - implementar e disseminar campanhas de educação, conscientização e informação; IV - instituir práticas de conduta e orientação de pais, familiares e responsáveis diante da identificação de vítimas e agressores; V - dar assistência psicológica, social e jurídica às vítimas e aos agressores; VI - integrar os meios de comunicação de massa com as escolas e a sociedade, como forma de identificação e conscientização do problema e forma de preveni-lo e combatê-lo; VII - promover a cidadania, a capacidade empática e o respeito a terceiros, nos marcos de uma cultura de paz e tolerância mútua; VIII - evitar, tanto quanto possível, a punição dos agressores, privilegiando mecanismos e instrumentos alternativos que promovam a efetiva responsabilização e a mudança de comportamento hostil; IX - promover medidas de conscientização, prevenção e combate a todos os tipos de violência, com ênfase nas práticas recorrentes de intimidação sistemática (bullying), ou constrangimento físico e psicológico, cometidas por alunos, professores e outros profissionais integrantes de escola e de comunidade escolar. O Art. $5^{\circ}$ trata da incumbência, portanto, daquilo que é necessário fazer e a quem é cabível fazer, assim, é dever do estabelecimento de ensino, dos clubes e das agremiações recreativas assegurar medidas de conscientização, prevenção, diagnose e combate à violência e à intimidação sistemática (bullying). Em seu Art. $6^{\circ}$, ficam determinados a produção e publicação de relatórios bimestrais das ocorrências de bullying, abrangendo Estados e Municípios, com a finalidade de planejamento de ações. O Art. $7^{\circ}$ deixa em aberto as possíveis parcerias para a implementação do Programa instituído pela Lei 13.185, que entrou em vigor em 2015.

Recentemente, alterando o Art. 12 da Lei de Diretrizes e Bases da Educação Nacional, Lei $\mathrm{n}^{\circ}$. 9394/1996, entrou em vigor a Lei $n^{\circ} 13.663 / 2018$, determinando que, dentre as incumbências das escolas, junto às ações destinadas à erradicação do bullying, sejam incluídas ações que promovam a cultura de paz, que tem como princípios: respeitar a vida; rejeitar a violência; ser generoso/a; ouvir para compreender; preservar o planeta; e, redescobrir a solidariedade.
Esta Lei concede especial atenção ao bullying.

Ambas leis federais instituídas (a Lei 13.185/2015 e a lei 13.663/2018) são de grande importância, pois além de conceituar e delimitar o bullying e seus atores, elas dão as diretrizes que devem ser seguidas a respeito do preparo das escolas para lidar com este fenômeno perverso, com efeitos deletérios em curto, médio e longo prazo sobre o desenvolvimento bio-psico-sociocultural-espiritual de crianças e adolescentes; uma vez que estão sujeitos a tantas vulnerabilidades e podem ser afetados em seu desenvolvimento cognitivo, na aquisição de habilidades sociais, tornando-os mais vulneráveis na sua inserção social e no exercício da cidadania, além do risco daqueles que se encontraram como vítimas mudarem de posição e se tornarem agressores como forma de retribuição.

A produção de leis é uma forma que o Estado possui de combater o bullying. Ao criar normas, o Poder Público poderá produzir maior estabilidade de maneira a reduzir a insegurança jurídica acerca do tema.

As leis podem ser importantes medidas tomadas em políticas públicas, desde que se obtenham resultados satisfatórios a partir de sua implementação. Uma forma adequada de mensurar se a "lei antibullying" é eficaz no combate à prática do bullying será, realmente, aplicar meios de diagnose, que darão parâmetros tanto em relação ao seu alcance no auxílio às instituições de ensino e demais instituições abordadas pela lei, bem como em relação ao não atendimento às determinações da própria lei pelas instituições.

As leis têm como função controlar e disciplinar os comportamentos e ações dos indivíduos de acordo com os princípios de uma determinada sociedade, para o enfrentamento de um problema, sendo dessa forma uma obrigação imposta. No entanto, mesmo quando bem aplicada e monitorada por instrumentos de controle, como a Lei 12.760/2012, conhecida como "Lei Seca", fazendo uma analogia, nota-se que não tem sido capaz de combater todos os acidentes de trânsito ocasionados pela ingestão excessiva de álcool, sendo que a sua função se restringe em nortear a sociedade para o enfrentamento do problema. Logo, é notório que nenhuma lei será capaz de erradicar o bullying por si só. Entende-se que, as políticas de enfrentamento ao bullying terão poucos efeitos se trabalhadas sozinhas pela escola, uma vez que este é um fenômeno cujos 
danos afetam múltiplos atores e contextos sociais, contudo, entende-se também que práticas de abordagem interdisciplinar possam oferecer formas de abordar e reduzir as consequências trazidas por esse fenômeno. A política antibullying, além de estimular que se informem as ocorrências dos casos de bullying, deve proteger a todos os atores envolvidos (quem recebe, quem testemunha e quem comete o bullying), oferecer informações adequadas aos pais, aos professores e à comunidade, bem como promover a socialização do menor na escola com transmissão da importância de se viver em uma sociedade democrática, que respeita os direitos individuais, sem perder de vista os deveres de cada um. Por tudo isso, um passo fundamental de conscientização social referente às políticas públicas antibullying é o conhecimento da legislação e do conteúdo de suas diretrizes, como dispositivos de proteção ao invés de dispositivo de repreensão ou mesmo de punição.

Assim, considerando todas as legislações citadas neste artigo, pode-se dizer que a comunidade envolvida pode estar negligenciando a erradicação do bullying, mais pela falta de iniciativas práticas do que pela carência de dispositivos legais apropriados, tendo ainda a considerar a recente oferta de discussão jurídica acerca de um tema que é, desde sempre, tão urgente.

\section{Considerações Finais}

Notadamente, há uma década, apenas, teve inicio no Brasil a preocupação em legislar, ou seja, estabelecer normas para o combate ao bullying. Alguns fatores primordiais têm prejudicado o bom andamento das ações contra o bullying como: a ausência dos pais na vida escolar de seus filhos, o desinteresse dos alunos, as burocracias do poder público, a desvalorização e a sobrecarga dos educadores, a estrutura física inadequada dos estabelecimentos de ensino e a não implementação de políticas públicas.

Contudo, é possível pensar num circulo virtuoso em que a incorporaçao de uma cultura de paz pode contribuir para eliminar o bullying e a eliminação do bullying pode promover a cultura de paz, incindindo positivamente, inclusive, na mediaçáo de conflitos e em outras formas de violências também presentes no cenário escolar. No entanto, está claro que não se trata de tarefa fácil, pois este fênomeno é complexo, com diversas causas determinantes, de configuração repetitiva e ações e intenções que causam sofrimento a um ou mais indivíduos. Outrossim, considera-se que, por meio de estudos, investimentos da promoção de conscientização geral (escola, pais, alunos, poder público e profissionais especializados), novos caminhos possam ser estabelecidos, reafirmando as escolas como locais de segurança, conhecimento e abertura para novos horizontes.

Considerando as limitações do estudo realizado, compreende-se, ainda assim, que algumas formas de contribuição podem ser sugeridas para o trabalho mais harmonioso quanto aos dissensos e os consensos em torno do fenômeno bullying e as legislações para o seu enfrentamento e erradicação:

1. Primeiramente, criar uma equipe interdisciplinar conveniando serviços de assistência pedagógica, médica, psicológica e jurídica.

2. Capacitar os colaboradores da escola para análise e encaminhamento de casos de bullying, quando necessário, à equipe de apoio multidisciplinar, visando auxiliar vítima, agressor, familiar e observador/testemunha.

3. Envolver a comunidade escolar, incluindo os pais, nas ações de conscientização, prevenção e combate ao bullying.

4. Adequar o regimento interno e apresentá-lo à comunidade juntamente com as legislações existentes;

5. Estando todos familiarizados com o fenômeno, a escola e os pais poderão identificar os sinais emitidos pela vítima, sendo um dos mais clássicos a ausência de vontade de frequentar a escola, bem como ansiedade, medo e baixa autoestima.

6. Diagnosticada a ocorrência do bullying, o professor ou outro profissional capacitado poderá chamar os envolvidos, focando na recuperação de valores essenciais, como o respeito, a empatia, a cooperação, a apreciação, dentre outros valores fundamentais para o viver em conjunto.

7. Não cessando a prática, os casos deverão ser encaminhados para o apoio interdisciplinar. 
8. Apenas em última instância deverá partir para uma ação mais enérgica, buscando o apoio efetivo do Conselho Tutelar e Ministério Público, para advertência dos agressores, visando assim diminuir ou até extinguir a repetição da prática.

\section{REFERÊNCIAS}

ACRE. Assembléia Legislativa do Estado Acre. Lei $n^{\circ}$ 2436/2011. Institui o Programa de Combate ao Bullying nas escolas públicas e privadas do Estado. Disponível em: http://www.aleac.net/lei/2012/01/lein-2436-de-22-de-julho-de-2011. Acesso em: 10 abr. 2014.

ADJORISC. Pesquisa da OAB/SC indica que bullying ainda é praticado em escolas públicas, 2013. Disponível em: http://www.adjorisc.com.br/educac-o/pesquisa-da-oab-sc-indica-que-bullying-ainda-e -praticado-em-escolas-publicas-1.1403864\#.VWVKG9JVikp Acesso em: 02 fev. 2015.

ALAGOAS. Assembléia Legislativa do Estado Alagoas. Lei $\mathbf{n}^{\circ} \mathbf{7 2 6 9 / 2 0 1 1}$. Institui o dia 7 de abril como o dia de combate ao bullying nas escolas públicas estaduais de Alagoas. Disponível em: http://www.gabinetecivil.al.gov.br/legislacao/leis/leis-ordinarias/2011/ lei-ordinaria-7.269. Acesso em: 10 abr. 2014.

AMAPÁ. Assembléia Legislativa do Estado Amapá. Lei $n^{\circ}$ 1527/2010. Institui o Programa de Combate ao "bullying" nas escolas públicas e privadas do Estado do Amapá. Disponível em: http://www.al.ap. gov.br/ver texto lei.php?iddocumento=27806. Acesso em: 10 abr. 2014.

AMAZONAS. Assembléia Legislativa do Estado Amazonas. Projeto de Lei 49/2011. Dispõe sobre o desenvolvimento de política "antibullying" por instituições de ensino e de educação infantil, públicas ou privadas, com ou sem fins lucrativos e dá outras providências. Disponível em: http://legislador.aleam.gov.br/ LegisladorWEB/LegisladorWEB.ASP?\%20WCI=ProjetoTexto \&ID=201\&INEspecie $=1 \&$ nrProjeto $=49 \&$ aaProjeto $=2011 \& d s$ Verbete=BULLYING. Acesso em: 08 set. 2014.

Portanto, se a escola, que tem o objetivo de promover o ensino, a aprendizagem e a educação em parceria com a família e a sociedade em favor de crianças, adolescentes e jovens, estiverem capacitados e seguindo as legislações existentes, sustentarão a dignidade humana, igualdade e outros constituintes básicos.
Calendário Oficial do Estado do Amazonas o dia 07 de abril, "Dia de Combate ao Bullying nas escolas públicas e privadas". Disponível em: http://legislador.aleam.gov.br/LegisladorWEB/LegisladorWEB. ASP?WCI=LeiTexto\&ID=201\&inEspecieLei=21\&n$\underline{\mathrm{rLe} i=110 \& \text { aaLei }=2011 \& d s \text { Verbete=bullying. }}$ Acesso em: 10 abr. 2014.

BRASIL. Lei $n^{\circ}$ 13.185, de 6 de novembro de 2015. Institui o Programa de Combate à Intimidação Sistemática (Bullying). Disponível em: http://www.planalto.gov.br/ccivil 03/ ato2015-2018/2015/lei//13185. htm. Acesso em: 06 nov. 2017.

BRASIL. Lei $\mathbf{n}^{\circ} \mathbf{1 3 . 6 6 3}$, de 14 de maio de 2018. Altera o art. 12 da Lei $n^{\circ} 9.394$, de 20 de dezembro de 1996. Disponível em: https://www.planalto.gov.br/ ccivil 03/_ato2015-2018/2018/lei/l13663.htm. Acesso em: 06 mar. 2019.

Instituto Brasileiro de Geografia e Estatística (IBGE). Pesquisa Nacional de Saúde do Escolar, Rio de Janeiro, 2012. Disponível em: http://www. ibge.gov.br/home/estatistica/populacao/pense/2012/. Acesso em: 20 mar. 2015.

Instituto Brasileiro de Geografia e Estatística (IBGE). Pesquisa Nacional de Saúde do Escolar, Rio de Janeiro, 2013. Disponível em: http://teen.ibge.gov.br/noticias-teen/3633-violencia-contra-adolescentes. Acesso em: 15 abr. 2014.

Lei $\mathbf{n}^{0} \mathbf{9 . 3 9 4}$, de 20 de dezembro 1996. Estabelece as diretrizes e bases da educação nacional. Diário Oficial da União, Brasília, DF, 23 dez. 1996. Disponível em: http://www.planalto.gov.br/ccivil_03/ leis/19394.htm. Acesso em: 29 jul. 2014. 
CEARÁ. Assembléia Legislativa do Ceará. Lei no 14943/2011. Institui o Serviço Disque Denúncia de Combate ao Bullying no Estado do Ceará e dá outras providências. Disponível em: http://www.al.ce.gov. br/legislativo/legislacao5/leis2011/14943.htm. Acesso em: 10 abr. 2014.

COCOLO, Ana Cristina. Metade dos estudantes brasileiros já sofreu humilhações. Disponível em: https://www.unifesp.br/edicao-atual-entreteses/ item/2591-metade-dos-estudantes-brasileiros-ja-sofreu-humilhacoes. Acesso em: 09 de maio 2019.

COLTRO, Alex. A Fenomenologia: Um Enfoque Metodológico para Além da Modernidade. Caderno de Pesquisas em Administração, São Paulo, v. 1, n. 11, p. 37- 45, 2000.

COUTO, Marcia de M. M. I.do. Por que re-ler o Direito à luz da Fenomenologia. V. Cadernos da Escola da Magistratura Regional Federal da $2^{\text {a }}$ Região : fenomenologia e direito/ Escola da Magistratura Regional Federal, Tribunal Regional Federal da $2^{\text {a }}$ Região, Rio de Janeiro, v. 7, n. 2, p. 21-35, out. 2014.

DISTRITO FEDERAL. Câmara Legislativa do Distrito Federal. Lei $N^{\circ} 4.824 / 2012$. Institui o Dia da Conscientização contra o Bullying no Distrito Federal. Diário Oficial do Distrito Federal, Brasília, DF, 4 maio 2012. Disponível em: http://legislacao.cl.df.gov. br/Legislacao/consultaTextoLeiParaNormaJuridicaNJUR-226142! buscarTextoLeiParaNormaJuridicaNJUR.action. Acesso em: 10 abr. 2014.

Lei No $4.837 / 2012$. Dispõe so-

bre a instituição da política de conscientização, prevenção e combate ao bullying nos estabelecimentos da rede pública e privada de ensino do Distrito Federal e dá outras providências. Diário da Câmara Legislativa, Brasília, DF, 24 maio 2012. Disponível em: http://legislacao.cl.df.gov.br/Legislacao/consultaTextoLeiParaNormaJuridicaNJUR-227226!buscarTextoLeiParaNormaJuridicaNJUR.action. Acesso em: 10 abr. 2014.

Lei $n^{\circ} 5.267 / 2013$. Cria a Se-

mana de Combate ao Bullying e dá outras providências. Diário Oficial do Distrito Federal, Brasília, DF, 23 dez. 2013. Disponível em: http://legislacao.cl.df. gov.br/Legislacao/consultaTextoLeiParaNormaJuridicaNJUR-287575! buscarTextoLeiParaNormaJuridicaNJUR.action. Acesso em: 10 abr. 2014.
DUTRA, Leanna Silva Meirelles. Bullying: da questao legal ao possivel enfrentamento do fenômeno nas escolas. 2015. 99f. Dissertação (Mestrado em Ciências: Educação e Saúde na Infância e Adolescência) - Escola de Filosofia, Letras e Ciências Humanas, Universidade Federal de São Paulo, Guarulhos, 2015.

ESPIRÍTO SANTO. Assembléia Legislativa do Estado Espiríto Santo. Lei $\mathbf{n}^{\circ}$ 9653/2011. Institui o Dia da Conscientização contra o "Bullying" e dá outras providências. Disponível em: http://www3.al.es.gov. br/ales/producao-legislativa. aspx?tip $=5 \&$ num $=251 \& a-$ no=2010. Acesso em: 10 abr. 2014.

FANTE, Cleo; PEDRA, José Augusto. Bullying escolar: perguntas e respostas. Porto Alegre: Artmed, 2008. $141 \mathrm{p}$.

GIL, Antônio Carlos. Como elaborar projetos de pesquisa. 4. ed. São Paulo: Atlas, 2008.

GOIÁS. Assembléia Legislativa de Góias. Lei $n^{\circ} 17151 / 2010$. Dispõe sobre a inclusão de medidas de conscientização, prevenção, diagnose e combate ao "bullying" escolar no projeto pedagógico elaborado pelas escolas públicas e privadas de Educação Básica do Estado de Goiás, e dá outras providências. Disponível em: http://www.gabinetecivil.go.gov.br/pagina leis.php?id=9789. Acesso em: 10 abr. 2014.

GOMES, J. O; CARDOSO, E. R. S; SOUZA, E. M. de. A Análise Fenomenológica: da Filosofia aos Estudos Organizacionais. VIII Encontro de Estudos Organizacionais da ANPAD. Gramado, 2014. p. 1-13.

KÖCHE, José Carlos. Fundamentos de metodologia científica: teoria da ciências e prática da pesquisa. 15. ed. Petrópolis: Rio de Janeiro: Vozes, 1997.

MALTA, Débora Carvalho; PORTO, Denise Lopes; CRESPO, Claudio Dutra; et al. Bullying em escolares brasileiros: análise da Pesquisa Nacional de Saúde do Escolar (PeNSE 2012). Rev. bras. Epidemiol, São Paulo, v. 17, p. 92-105, 2014.

MARANHÃO. Assembléia Legislativa do Maranhão. Lei $n^{\circ}$ 9297/2010. Dispõe sobre a inclusão de medidas de conscientização, prevenção e enfrentamento ao bullying escolar no projeto pedagógico elaborado pelas instituições de ensino públicas e particulares no Estado do Maranhão, e dá outras providências. Disponível em: http://www.normasbrasil.com.br/norma/lei9297-2010-ma_130081.html. Acesso em: 10 abr. 2014. 
MARCOLINO, Emanuella de Castro; CAVALCANTI, Alessandro Leite; PADILHA, Wilton Wilney Nascimento.; et al. Bullying: prevalência e fatores associados à vitimização e à agressão no cotidiano escolar. Texto Contexto Enferm, v. 27, n. 1, 2018.

MATO GROSSO. Assembléia Legislativa do Mato Grosso. Lei $n^{\circ} \mathbf{9 7 2 4 / 2 0 1 2}$. Dispõe sobre a inclusão de medidas de conscientização, prevenção, diagnose e combate ao bullying escolar no projeto pedagógico elaborado pelas escolas públicas e privadas em todo o território mato-grossense, e dá outras providências. Disponível em: http://www.al.mt.gov.br/ leis/lei 5678.pdf. Acesso em: 10 abr. 2014.

MATO GROSSO DO SUL. Assembléia Legislativa do Mato Grosso do Sul. Lei $\mathbf{n}^{\circ} \mathbf{3 8 8 7 / 2 0 1 0}$. Dispõe sobre o Programa de inclusão de medidas de conscientização, prevenção e combate ao bullying escolar no projeto pedagógico elaborado pelas Instituições de Ensino e dá outras providências. Disponível em: http:// aacpdappls.net.ms.gov.br/appls/legislacao/secoge/govato.ns. Acesso em: 10 abr. 2014.

MINAS GERAIS. Assembléia Legislativa do Esta-

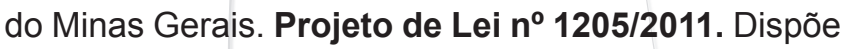
sobre o desenvolvimento de política "antibullying" por instituições de ensino e de educação infantil, públicas ou privadas, com ou sem fins lucrativos. Disponível em: http://www.almg.gov.br/atividade parlamentar/tramitacao_projetos/interna.html?a=2011\&n=1205\&t=PL. Acesso em: 8 set. 2014.

SANTOS, Mariana Michelena; KIENEN, Nádia. Características do Bullying na Percepção de Alunos e Professores de uma Escola de Ensino Fundamental.

Temas em Psicologia, v. 22, n. 1, p. 161-178, 2014.

OLWEUS, Dan. Conductas de acoso y amenaza entre escolares. $2^{\mathrm{a}}$ ed. Madrid: Morata, 2004.

PARAÍBA. Assembléia Legislativa da Paraíba. Lei ${ }^{\circ} \mathbf{8 5 3 8 / 2 0 0 8}$. Fica o Poder Executivo autorizado a instituir o Programa de Combate ao Bullying, de ação interdisciplinar e de participação comunitária, nas escolas públicas e privadas do Estado da Paraíba. Disponível em: http://alpb1.pb.gov.br:8082/sapl/sapl_documentos/norma juridica/8940 \%20texto \%20integral. Acesso em: 10 abr. 2014.
Lei $n^{\circ}$ 9.509/2011. Institui o

Dia e a Semana Estadual da Prevenção e Combate ao Bullying. Disponível em: http://alpb1.pb.gov.br:8082/ sapl/sapl documentos/norma juridica/10125 texto integral. Acesso em: 10 abr. 2014.

Lei $\mathbf{n}^{\circ} \mathbf{9} . \mathbf{8 5 8 / 2 0 1 2}$. Dispõe sobre penalidades às escolas públicas e privadas do Estado da Paraíba quando verificada a prática do bullying, e dá outras providências. Disponível em: http://alpb1. pb.gov.br:8082/sapl/sapl_documentos/norma_juridica/10952 texto integral. Acesso em: 10 abr. 2014.

PARANÁ. Assembléia Legislativa do Paraná. Lei $n^{\circ}$ 17335/2012. Institui o Programa de Combate ao Bullying, de ação interdisciplinar e de participação comunitária, nas Escolas Públicas e Privadas do Estado do Paraná. Disponível em: http://www.legislacao.pr.gov. br/legislacao/pesquisarAto.do?action=exibir\&codAto $=77838 \&$ indice $=1 \&$ totalRegistros $=1$. Acesso em: 10 abr. 2014.

PERNAMBUCO. Assembléia Legislativa do Pernambuco. Lei $n^{\circ}$ 13.995/2009. Dispõe sobre a inclusão de medidas de conscientização, prevenção, diagnose e combate ao bullying escolar no projeto pedagógico elaborado pelas escolas públicas e privadas de educação básica do Estado de Pernambuco. Disponível em: http://legis.alepe.pe.gov.br/arquivoTexto.aspx?tiponor$\underline{\mathrm{ma}=1 \& \text { numero }=13995 \& \text { complemento }=0 \& a n o=2009 \&-}$ tipo=TEXTOATUALIZADO. Acesso em: 10 abr. 2014.

Lei $n^{\circ}$ 14.528/2011. Institui, no Calendário Oficial de Eventos do Estado de Pernambuco, o Dia de Combate ao Bullying. Disponível em: <http://legis.alepe.pe.gov.br/arquivoTexto. aspx?tiponorma $=1 \&$ numero $=14528 \&$ complemento=0\&ano=2011\&tipo $>$. Acesso em: 10 abr. 2014.

PIAUÍ. Assembléia Legislativa do Estado Piauí. Lei $n^{\circ}$ 6076/2011. Dispõe sobre o enfrentamento da prática de bullying por instituições de ensino fundamental e médio, públicas ou privadas, no Estado do Piauí. Disponível em: http://servleg.al.pi.gov.br:9080/ ALEPI/consultas/norma juridica/norma juridica mostrar_proc?cod_norma=561. Acesso em: 10 abr. 2014. 
RIO DE JANEIRO. Assembléia Legislativa do Rio de Janeiro. Lei $n^{\circ}$ 6401/2013. Institui a "Semana de combate ao bullying e ao cyberbullying" nas escolas públicas da rede estadual do Rio de Janeiro. Altera a Lei Estadual $n^{\circ} 5.645$, de 6 de janeiro de 2010, e dá outras providências. Disponível em: http://www.alerj. ri.gov.br/processo2.htm. Acesso em: 10 abr. 2014.

.Lei $n^{\circ}$ 6616/2013. Torna obrigatória a exibição de propaganda publicitária esclarecendo as consequências do assédio moral, bullying antes das sessões de filmes nos cinemas e dá outras providências. Disponível em: http://www.alerj. rj.gov.br/processo2.htm. Acesso em: 10 abr. 2014.

RIO GRANDE DO NORTE. Lei $\mathbf{n}^{\circ} \mathbf{1 0 . 4 1 8 / 2 0 1 8 . ~}$ Dispõe sobre a inclusão no calendário oficial do Estado do Rio Grande do Norte a "Semana de Combate ao Bullying e ao Cyberbullying", a ser instituído na primeira semana do mês de abril, e dá outras providências. Disponível em: https://www.legisweb.com.br/legislacao/?id=366097. Acesso em: 10 de maio 2019.

RIO GRANDE DO SUL. Assembléia Legislativa do Estado Rio Grande do Sul. Lei no 13.474/2010. Dispõe sobre o combate da prática de "bullying" por instituições de ensino e de educação infantil, públicas ou privadas, com ou sem fins lucrativos. Disponível em: http://www.al.rs.gov.br/legis/M010/M0100099.ASP?Hid Tipo $=$ TEXTO\&Hid TodasNormas $=54438 \& \mathrm{~h}-$ Texto $=\&$ Hid IDNorma $=54438$. Acesso em: $10 \mathrm{abr}$. 2014.

RONDÔNIA. Assembléia Legislativa do Estado Rondônia. Lei $n^{\circ}$ 2.590/2011. Dispõe sobre a criação do Dia de Combate ao Bullying no âmbito do Estado de Rondônia. Disponível em: http://sapl.al.ro.leg.br/ sapl documentos/norma juridica/5509 texto integral. Acesso em: 10 abr. 2014.

Lei $n^{\circ}$ 2.621/2011. Autoriza o Poder Executivo a instituir o programa de combate ao Bullying, de ação interdisciplinar e de participação comunitária, nas escolas da rede de ensino público e particular do Estado de Rondônia. Disponível em: http://sapl.al.ro.leg.br/sapl_documentos/norma juridica/5536 texto integral. Acesso em: 10 abr. 2014.
SANTA CATARINA. Assembléia Legislativa do Estado Santa Catarina. Lei 14651/2009. Fica o Poder Executivo autorizado a instituir o Programa de Combate ao Bullying, de ação interdisciplinar e de participação comunitária nas escolas públicas e privadas do Estado de Santa Catarina. Disponível em: http://200.192.66.20/ALESC/PesquisaDocumentos.asp. Acesso em: 10 abr. 2014.

SERGIPE. Assembléia Legislativa do Estado

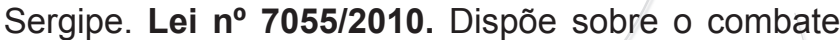
da prática de "bullying" por instituições de ensino e de educação, públicas ou privadas, com ou sem fins lucrativos e dá providências correlatas. Disponível em: http://www.al.se.gov.br/Detalhe Lei Imprimir.asp?Numerolei=7605. Acesso em: 10 abr. 2014.

SILVA, Ana Beatriz Barbosa. Bullying: mentes perigosas nas escolas. Rio de Janeiro: Fontanar, 2010. $188 \mathrm{p}$.

SILVA, Fernanda; DASCANIO Denise; VALLE, Tânia Gracy Martins. O fenômeno bullying: diferenças entre meninos e meninas. Revista Reflexão e Ação, v. 24 , n. 1 , p. 26 - 46, Jan/Abr. 2016. Disponível em: http://online.unisc.br/seer/index.php/reflex/index Acesso em: 06 mar. 2019.

TSITSIKA, Artemis Kimon; BARLOU, Efi; ANDREI, Elisabeth; et al. Bullying behaviors in children and adolescents: "an ongoing story". Front Public Health. [Internet]. 2014 Feb [cited 2015 Sep 13]; v. 2, n. 7, p:1-4. Disponível em: https://www.nlm.nih.gov/

VERGARA, Sylvia Constant. Projetos e relatórios de pesquisa em administração. $2^{a}$ ed. São Paulo: Atlas, 1998. 